\section{NSF stance on 'skills shortage'}

SIR - Jeffrey Mervis's article on the controversy surrounding trends in degree acquisition (Nature 356, 553; 1992) deserves comment.

Having come to this issue after the fact, I have had the benefit of examining it with a fresh perspective and have approached it in as objective a manner as possible. Nothing in my review suggests to me that there was a deliberate attempt on the part of the National Science Foundation (NSF) to misinform.

Both our friends and critics ask how this narrow study of degree attainment could assume the status of an authoritative labour market projection of demand for scientists and engineers. In response, I would say that, with the benefit of hindsight, the shortcomings of this limited analysis seem self-evident. The widespread use of the study beyond that which its narrow scope could support has served for me as an object lesson that sins of omission can be as important as sins of commission. The NSF now has in place procedures to forestall a similar occurrence. Publications released under the NSF imprimatur will meet the high standards we have set for ourselves and the expectations others have of us.

NSF continues to give high priority to improving the quality of education. The contention that we can have too many citizens with a good grounding, at various levels, in mathematics, the sciences and engineering is untenable, given the broad challenges of our developing economy in the years to come. With this in mind, we will continue to conceive and support programmes to nurture technical knowledge and skills and ensure the development of the scientific and engineering talent to meet future needs.

\section{Walter E. Massey}

\section{(Director)}

National Science Foundation,

1800 Q Street, NW,

Washington, DC 20550, USA

\section{Lithuania's need}

SIR - I write in response to your leading articles of 23 January and 20 February (Nature 355, 283 \& 659; 1992). The latter referred to the "disconcerting . . . tendency for the world to be sprinkled with small countries" and seemed to support those who would argue that small countries should be ineligible by reason of size to self-determination and, as victims of oppression, are untrustworthy to govern themselves and their minorities fairly.

You assert that minorities in the newly independent "microstates" are in immediate danger of oppression and specifically question whether the Baltic states are protecting the rights of their Russian minorities. Our law clearly states that Lithuania "shall guarantee to all its citizens, regardless of ethnicity, equal political, economic and social rights and freedoms, shall recognize its citizens' ethnic identity, the continuity of their culture, and shall promote ethnic consciousness and the expression thereof."

These expressions include statesupported Russian, Polish and Hebrew language schools, contact with people of the same ethnic background abroad, and religious or folk observances in one's native language. In short, there is not, nor has there been, any oppression of national minorities in Lithuania.

Furthermore, contrary to the reasoning in your leading article of 30 January (Nature 355, 377; 1992), the scientific and economic value of the former Soviet Union is immeasurably exceeded by the sum of its smaller parts. In order to be able to sustain itself in the short term and to prosper in the coming years, Lithuanian science needs the journals, the travel, the research support now being advocated only for Russia. A modest sum of money concentrated in a small country goes much further than a large amount of money scattered throughout a massive country.

\section{Stasys Lozoraitis}

(Ambassador to the

United States of America)

Lithuanian Embassy,

Washington, DC 20009, USA

\section{Life on a grant}

SIR - Howard Morris (Nature 356, 10; 1992) and M. J. Clemens (356, 280; 1992) referred to the increasing difficulty of recruiting research students without specifically identifying the biggest disincentive to postgraduate study, namely the ludicrously inadequate size of maintenance grants. At the launch of Nature's "Manifesto for British Science" last September, the head of the Science and Engineering Research Council (SERC), Sir Mark Richmond, declared that the annual stipend for $\mathrm{PhD}$ research students was "a national disgrace".

Since his comments, both SERC and the Natural Environment Research Council (NERC) have announced small rises in their basic awards to $£ 4,300$ a year, with NERC adding a further increment next October of $£ 500$ to first and second years and $£ 1,000$ to third years.

Thus, a maintenance grant from NERC or SERC (taking income tax, national insurance and 'poll tax' allowances into account) is equivalent to fulltime employment on less than $£ 5,500$ per year. Compare with the average starting salary of $£ 11,681$ for a graduate in science and engineering or the $£ 7,000$ that would be earned by the lowest paid full-time workers if there was a national minimum wage of $£ 3.40$ an hour.

Is it any wonder that, after striving for three or four years to attain a first or upper second class degree, graduates decide against another three years of debt accumulation to obtain a $\mathrm{PhD}$ ? Indeed, it is amazing that anybody can afford to become a postgraduate after experiencing the abject poverty that accompanies undergraduate life these days. It may well be difficult to convince graduates that they should forsake a living wage in favour of academic research at the moment, but it will surely be an even more arduous task once the graduate job market recovers from its present depression.

However, just as Morris claims that the Committee of Vice-Chancellors and Principals has been reluctant to "argue the case vigorously for fair rewards for Britain's academic teachers and researchers", postgraduates may make the same accusation of their paymasters, the research councils. What are we to make of the current lack of agreement on the rate of awards for three-year studentships? SERC offers $£ 4,300$ a year, NERC $£ 4,800$, the Agricultural and Food Research Council $£ 5,000$ (soon to be $\{5,500$ or more), and the Medical Research Council £5,590.

I agree with the recommendation in Nature's manifesto that a "doubling of present rates would be simple and equitable". Who else shares this view?

\section{Bob Ward}

Department of Geology, The University, Manchester M13 9PL, UK

\section{Born to it}

SIR - Richard Peto's Commentary (Nature 356, 557; 1992) misses an important aspect of how to go about controlling chronic diseases that kill adults in middle age. David Barker at Southampton University in the United Kingdom has discovered a relationship between various perinatal factors and the subsequent likelihood of developing certain chronic conditions in adult life. Placental mass, for example, seems to be independently correlated with adult blood pressure decades later, and the duration of breast feeding seems to be correlated with adult blood cholesterol levels. Perhaps, to follow the course Peto suggests, we need to pay more attention to the conditions in which children are born.

Olivia Judson

New College,

Oxford OX1 3BN, UK 